\title{
Cytokine storm in COVID-19: pathogenesis and overview of anti-inflammatory agents used in treatment
}

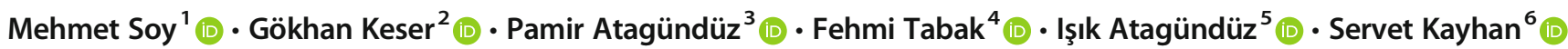

Received: 1 May 2020 /Revised: 1 May 2020 / Accepted: 19 May 2020 / Published online: 30 May 2020

(C) International League of Associations for Rheumatology (ILAR) 2020

\begin{abstract}
COVID-19 infection has a heterogenous disease course; it may be asymptomatic or causes only mild symptoms in the majority of the cases, while immunologic complications such as macrophage activation syndrome also known as secondary hemophagocytic lymphohistiocytosis, resulting in cytokine storm syndrome and acute respiratory distress syndrome, may also occur in some patients. According to current literature, impairment of SARS-CoV-2 clearance due to genetic and viral features, lower levels of interferons, increased neutrophil extracellular traps, and increased pyroptosis and probable other unknown mechanisms create a background for severe disease course complicated by macrophage activation syndrome and cytokine storm. Various genetic mutations may also constitute a risk factor for severe disease course and occurrence of cytokine storm in COVID-19. Once, immunologic complications like cytokine storm occur, anti-viral treatment alone is not enough and should be combined with appropriate anti-inflammatory treatment. Anti-rheumatic drugs, which are tried for managing immunologic complications of COVID-19 infection, will also be discussed including chloroquine, hydroxychloroquine, JAK inhibitors, IL-6 inhibitors, IL-1 inhibitors, anti-TNF- $\alpha$ agents, corticosteroids, intravenous immunoglobulin (IVIG), and colchicine. Early recognition and appropriate treatment of immunologic complications will decrease the morbidity and mortality in COVID-19 infection, which requires the collaboration of infectious disease, lung, and intensive care unit specialists with other experts such as immunologists, rheumatologists, and hematologists.
\end{abstract}

Keywords COVID-19 Cytokine storm syndrome $\cdot$ Hemophagocytic lymphohistiocytosis $\cdot$ Macrophage activation syndrome

Mehmet Soy

mhmtsoy@gmail.com

Gökhan Keser

agkkeser@gmail.com

Pamir Atagündüz

pamir.atagunduz@gmail.com

Fehmi Tabak

fehmitabak@yahoo.com

Iş1k Atagündüz

ikatagunduz@gmail.com

Servet Kayhan

servet.kayhan@altinbas.edu.tr

1 Internal Medicine and Rheumatology, Department of Internal Medicine, Faculty of Medicine, Division of Rheumatology, Bahcelievler MedicalPark Hospital, Altinbas University (Previously Kemerburgaz University, Istanbul, Turkey
2 Internal Medicine and Rheumatology, Department of Internal Medicine, Faculty of Medicine, Division of Rheumatology, Ege University, Izmir, Turkey

3 Internal Medicine and Rheumatology, Department of Internal Medicine, Faculty of Medicine, Division of Rheumatology, Marmara University, Istanbul, Turkey

4 Internal Medicine and Infectious Disease, Department of Infectious Diseases, Cerrahpasa School of Medicine, Istanbul University-Cerrahpasa, Istanbul, Turkey

5 Internal Medicine and Hematology, Department of Internal Medicine, Faculty of Medicine, Division of Hematology, Marmara University, Istanbul, Turkey

6 Bahcelievler MedicalPark Hospital; Department of Chest Disease, Faculty of Medicine, Altinbas University (Previously Kemerburgaz University), Istanbul, Turkey 


\section{Introduction}

Coronavirus disease 2019 (COVID-19) is a clinical syndrome, caused by a mutational RNA virus named as Severe Acute Respiratory Syndrome CoronaVirus 2 (SARS-CoV-2). After initially occurring in China in December 2019, it spread all over the world and accepted as a pandemic by the World Health Organization (WHO) in March 11, 2020. SARSCoV-2, is a beta-coronavirus, similar to two other coronaviruses causing deadly infections during the last two decades, i.e. Severe Acute Respiratory Syndrome Corona Virus (SARS-CoV) and the Middle East Respiratory Syndrome Corona Virus (MERS-CoV) [1].

Although SARS-CoV-2 infections may be asymptomatic or cause only mild symptoms in the majority of the cases and less lethal than MERS-CoV infections, it may progress to interstitial pneumonia and acute respiratory distress syndrome (ARDS) in nearly $10-20 \%$ of the cases, especially in those having older age and co-morbidities. This subgroup of patients is notable with having very high levels of serum ferritin and D-dimer levels, hepatic dysfunction, thrombotic tendency, and disseminated intravascular coagulation (DIC) implicating occurrence of macrophage activation syndrome (MAS), also known as secondary hemophagocytic lymphohistiocytosis (sHLH) [2, 3]. Similar clinical and laboratory findings were also reported in patients with SARS-CoV and MERS-CoV infections [1,2].

In this context, we aimed to review COVID-19 infection, with special reference to its relationship with cytokine storm. For this purpose, PubMed and Google Academic were searched from April 11 to 26, 2020. Original data in all studies (including case reports and case series) that addressed the definition, causes, and classification of COVID-19 and hemophagocytosis, MAS, hemophagocytic lymphohistiocytosis, and cytokine storm, published in the English language in peer-reviewed journals, were included. An additional search for fulltext articles with the same keywords was performed in the databases, subscribed by Altınbaş University.

Results of our search were outlined as follows: firstly we discussed the pathogenesis and immunologic features in COVID-19 infection, followed by normal interactions between innate immune system and viruses, background for cytokine storm secondary to COVID-19 infection, and finally the management of the immunologic complications.

\section{Pathogenesis of COVID-19 infection}

Fever, dry cough, shortness of breath, myalgia, fatigue, a tendency for leucopenia, and radiological signs of progressive pneumonia, which may cause ARDS, are similar clinical and laboratory findings seen in COVID-19, SARS-CoV, and MERS-CoV infections. This may suggest that their pathogenesis may also be similar [2]. We believe that any hypothesis covering COVID-19 pathogenesis should explain very high serum levels of both ferritin and D-dimer levels disproportionate with the severity of infection, as well as a tendency for monocytosis, rather than lymphocytosis, including a low number of natural killer (NK) and cytotoxic T cells, and finally tendency for DIC. Indeed, these striking features mainly reflect the presence of MAS and cytokine storm.

Spike glycoproteins are the most immunogenic parts of the coronaviruses, which may bind to angiotensin-converting enzyme-2 (ACE-2) receptors to enter the host cell. Similarities were shown between spike glycoproteins of SARS-CoV and SARS-CoV-2. Distribution of ACE-2 receptor expression intensely on the surface of alveolar epithelial type II cells, cardiac, renal, intestinal, and endothelial cells is consistent with the target organs involved and the clinical picture in COVID19 infection $[2,4]$.

SARS-CoV-2 spreads primarily with direct contact through droplets of saliva or discharge from the respiratory tract, when an infected person coughs or sneezes [1]. Following binding to the cell surface receptor of ACE-2 by the spike glycoprotein, it enters the cell cytoplasm, where it releases RNA genome and replicates, resulting in the formation of new viral particles. Then, the cell disintegrates and the virus spreads to other cells.

As the immune system recognizes the viral antigens, antigen-presenting cells process these antigens and present them both to the natural killer and CD8-positive cytotoxic T cells in the context of major tissue histocompatibility (MHC) antigens as usual. This presentation activates both innate and adaptive immunity causing the production of large amounts of pro-inflammatory cytokines and chemokines. In some patients, this activation becomes so massive that cytokine storm develops, resulting in thrombotic tendency and multi-organ failure, and eventually causing death $[5,6]$.

Another pathogenic mechanism independent from binding to cell surface ACE-2 binding was also speculated, claiming that the virus might bind to the beta chain of porphyrins inside the erythrocytes, resulting in disturbance of heme metabolism and release of iron. However, this speculation needs further investigation and remains elusive $[7,8]$.

\section{Immunologic features in COVID-19 infection}

Zhang at al. reported that the number of $\mathrm{T}$ lymphocytes including both CD4 and CD8 subtypes and especially NK cells are much lower than expected in patients with severe disease course [9]. The number of regulatory T cells is also very low. Severe lymphopenia is a very early sign of the disease, preceding pulmonary problems, and tends to normalize as the patient improves. Lymphopenia is included among diagnostic criteria in China. Despite low numbers, both CD4 and CD8 positive lymphocytes express the high amount of HLADR4 
and CD38, showing hyperactivity. Additionally, CD8 T cells harbor high concentrations of cytotoxic granules; i.e., $31.6 \%$ were perforin positive, $64.2 \%$ were granulysin positive, and $30.5 \%$ were both granulysin and perforin positive. Total leukocyte and neutrophil counts and neutrophil/lymphocyte ratio (NLR) are increased especially in severe cases; NLR may be used as a follow-up parameter in patients with COVID-19 infection $[10,11]$. Generally, the number of CD8 T lymphocytes recovers in 2-3 months, whereas it may take nearly a year for the memory CD4 $\mathrm{T}$ lymphocytes to recover in SARS CoV infection [9-13].

Besides low numbers of peripheral lymphocytes, there is striking atrophy of the secondary lymphoid organs including the lymph nodes and spleen, confirmed by autopsy findings. Necrosis-associated lymph node and spleen atrophy, significant splenic cell degeneration, focal hemorrhagic necrosis, macrophage proliferation, and increased macrophage apoptosis in the spleen have been reported. Immunohistochemical staining showed decreased numbers of CD4 positive and CD8 positive T cells in the lymph nodes and spleen $[14,15]$.

On the other hand, monocytes and macrophages are increased, which may explain elevated levels of proinflammatory cytokines such as interleukin (IL)-6, IL-1, tumor necrosis factor (TNF) $\alpha$, and IL-8, which in some patients turn out to be a cytokine storm, as discussed more in detail later.

The great majority of the inflammatory cells infiltrating the lungs are monocytes and macrophages. Autopsy findings showed the presence of monocytes and macrophages and a moderate amount of multinucleated giant cells associated with a diffuse alveolar injury. However, pulmonary infiltrating lymphocytes were scarce and mostly CD4 positive. These findings were not different than those reported for patients with SARS-CoV and MERS-CoV infections [14].

In patients with COVID-19, elevated D-dimer levels are important and persistent elevation confers to poor prognosis. Development of DIC is another problem, characterized by prolongation of prothrombin time and activated partial thromboplastin time, high fibrin degradation products, and severe thrombocytopenia, which may be life-threatening [16].

Thrombotic tendency in COVID-19 patients is probably caused by endothelial cell activation or damage due to viral binding to the ACE-2 receptor. The presence of traditional risk factors for venous thromboembolism was found to be high among COVID-19 patients. High levels of inflammatory mediators and immunoglobulins may lead to higher blood viscosity; mechanical ventilation and vascular interventions such as central venous catheterization may further induce vascular endothelial damage in severe or critically ill patients. Anticardiolipin antibody levels were also found to be high in small groups reported. The combination of all these factors may lead to deep vein thrombosis or even possibly to lethal pulmonary thromboembolism. Therefore, COVID-19- infected patients, whether hospitalized or ambulatory need early and prolonged prophylaxis with low molecular weight heparin $[9,16]$. On the other hand, ischemic changes in the fingers and toes mimicking vasculitis have been reported in patients with severe COVID-19 [13].

The quick interpretation of these issues outlined above shows that the disease starts as a simple viral infection but goes out of control after a while and progresses towards a deadly result with development of the cytokine storm and serious organ damage. To understand why and how this process occurs, and what we can do to control this process, we need to know further details of the pathogenesis of COVID-19 and cytokine storm.

\section{Normal interactions between innate immune system and viruses}

In the context of the normal innate immune system, macrophages, monocytes, dendritic cells, and neutrophils express a variety of pattern recognition receptors (PRRs) that detect pathogen-associated molecular patterns (PAMPs), which are expressed by infectious agents. Among PRRs, the membranebound family of toll-like receptors (TLRs) recognizes mainly the PAMPs in the extracellular and to a lesser account in the intracellular milieu. The triggered signaling process leads to the expression of proinflammatory cytokine-inducing transcription factors, such as NF-kB, as well as to activate interferon regulatory factors that mediate the type I interferondependent antiviral response [17]. The second set of pathogen recognition sensors is present in the cytosol and includes another family of nucleotide-binding domain leucine-rich repeat (NLR) proteins (NLRP1, NLRP3, NLRP7, and NLRC4), the protein absent in melanoma 2 (AIM2), and pyrin. These sensors are essential for the detection of endogenous dangerassociated molecular patterns (DAMPs) expressed inside the cell. Binding of DAMPs activates NLRs, triggering the formation of multiprotein cytoplasmic complexes called inflammasomes, which convert procaspase- 1 to active caspase- 1 . Then, caspase- 1 converts proIL-1 $\beta$ to active IL- $1 \beta$, which is a very important proinflammatory cytokine $[17,18]$ (Fig. 1). It should be noted that if these signaling activation processes are kept under control, they serve for the benefit of the human body.

For the viruses, PAMPs are generally their nucleic acids. Viral RNA binds to endosomal TLR-3, TLR-7, and cytosolic receptors including RIG-I like receptors (RLR's). RLR family consists of three members, namely, retinoic acid-induced gene I (RIG-I), Melanoma Differentiation-Associated Gene 5 (MDA5), and Laboratory of Genetics and Physiology 2 (LGP2) $[19,20]$. Additionally, RIG-I and MDA5 have two CARDs ( $\mathrm{N}$ terminal caspase activation and recruitment domains). Upon binding of RNA with RLR, CARD interacts with MAVS (mitochondrial adaptor antiviral signal) protein, 


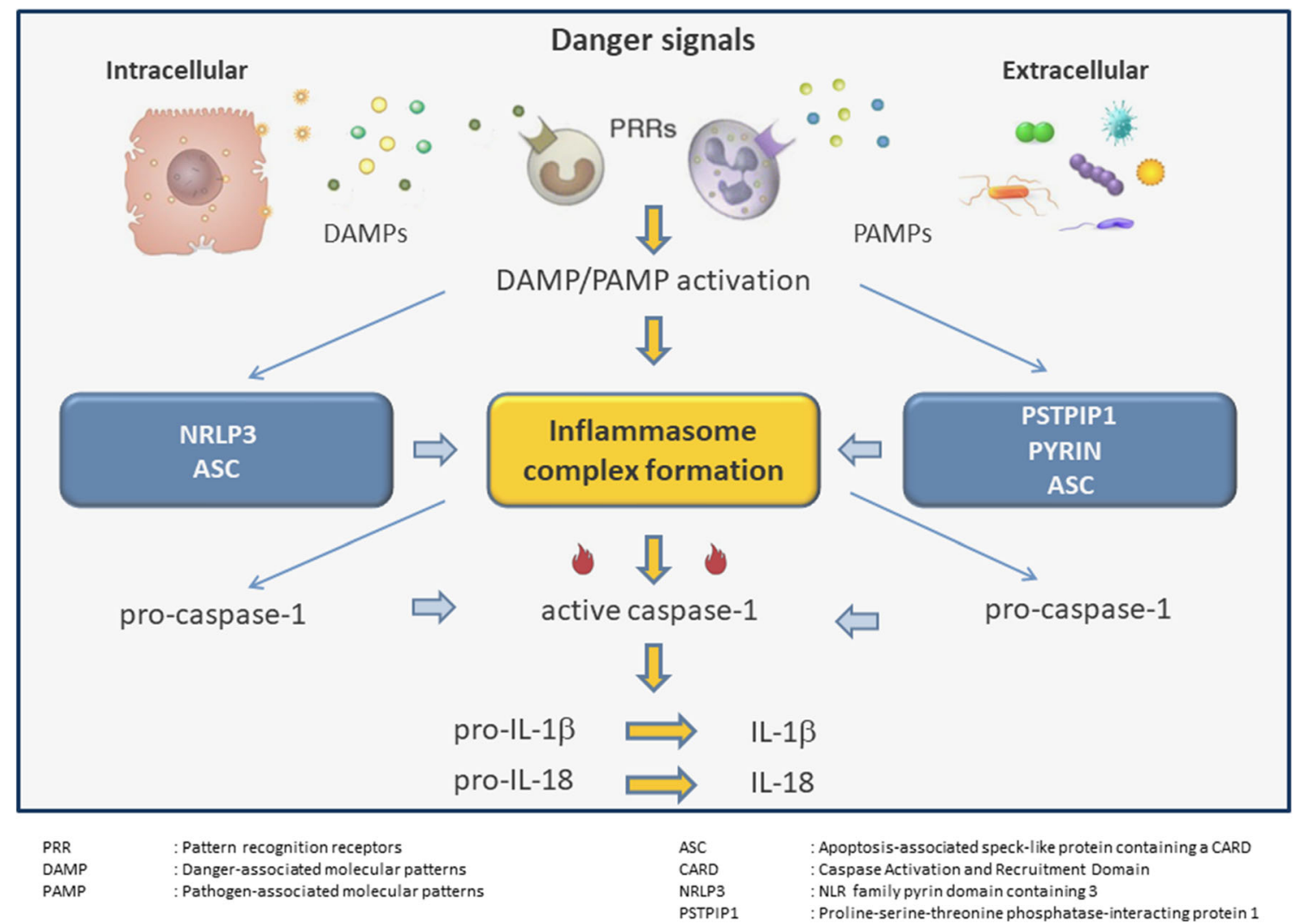

Fig. 1 Generation of inflammasome and IL-1 activation pathway

leading to activation of the gene coding type 1 interferons (IFNs). Type 1 IFNs play important roles in coordinating cellular immunity reactions to viral infections, thereby contributing to normal antiviral immunity [21].

In normal conditions, virus-infected cells are destroyed by NK cells of the innate immunity and CD8 positive cytolytic T cells of the adaptive immunity, using perforin-mediated granulysin secretion. This leads to apoptosis of antigenpresenting cells and relevant cytotoxic T cells to avoid unnecessary activation after the antigenic activity is over. However, if a defect occurs in lymphocyte cytolytic activity, whether due to genetic problems or acquired conditions, this may lead to the inability of NK and cytolytic CD8 T cells to lyse infected and activated antigen-presenting cells, resulting in prolonged and exaggerated interactions between innate and adaptive immune cells. In this case, many pro-inflammatory cytokines, including TNF, interferon- $\gamma$, IL-1, IL-6, IL-18, and IL-33, are secreted in an unrestrained way causing a cytokine storm. The whole pathologic process starting with defects in lymphocyte cytolytic activity, going on with increased macrophage activity and whole immune system activation, resulting in a cytokine storm, ARDS, and multiorgan failure, is also called as MAS $[3,22,23]$. This life-threatening condition is one of the major causes of death in COVID-19 patients.
There is no consensus or suggestion on which terminology should be used: cytokine storm, MAS, or sHLH? We chose to use the term cytokine storm secondary to COVID-19; however, it would not be irrefutable for anyone to use MAS or sHLH terminology.

\section{Background for MAS and cytokine storm during COVID-19 infection}

Among patients initially reported in Wuhan, the occurrence of MAS, cytokine storm, and ARDS were heralded by very high levels of serum pro-inflammatory cytokines and ferritin. In the past, significantly higher serum levels of IL-6, IFN- $\alpha$, CCL5, CXCL8, and CXCL-10 were also detected in patients with severe SARS-CoV or MERS-CoV infections compared to those with milder infections [24].

Clinical and laboratory features of MAS include sustained fever, elevated serum ferritin, and triglyceride levels, pancytopenia, fibrinolytic consumptive coagulopathy, liver dysfunction, and splenomegaly. Besides, low or absent NK cell activity, elevated serum levels of SCD25 and $\mathrm{sCD} 163$, and the presence of hemophagocytosis, which is defined as the engulfment of blood cells, including 
eryhrocytes, leucocytes, or platelets by phagocytic cells, support the diagnosis of MAS [3].

Proposed predisposing factors for MAS and cytokine storm secondary to COVID-19 infection are discussed below:

\section{(1) Impaired viral clearance}

The main problem in COVID-19 infection is impaired viral clearance, like SARS-CoV and MERS-CoV infections. These viruses have some strategies to combat against host defense mechanisms. SARS-CoV and MERS-CoV could produce vesicles having double membranes without PRRs, and to replicate inside these vesicles [25]. These strategies lead to impaired antiviral immune response and viral clearance. Although the PCR test is negative, the presence of virus inclusion bodies in pulmonary alveolar cells and macrophages at least for 2 weeks still supports the possibility of a failure of virus clearance [14].

\section{(2) Low levels of type I interferons}

Another contributing factor is low levels of type I interferons, which are indeed very important in anti-viral response and viral clearance [21]. Cellular proteins that recognize viral nucleic acids are mediated by stimulating interferons during viral infections. Recognition of viral RNA by MDA5 is essential for anti-viral immunity, and deficiency of MDA5 causes a tendency for viral infections in humans [26]. An accessory protein of MERS-CoV called as 4a, binds to doublestranded RNA, thereby blocking MDA5 activation and IFN induction [27]. It should be noted that people who died during the 1997 H5N1 influenza outbreak showed lymphoid tissue atrophy associated with high titer circulatory cytokines, including IL-6 [28]. Similar upregulation of pro-inflammatory cytokines together with downregulation of antiviral cytokine was observed in MERS-CoV infection [29].

\section{(3) Increased neutrophil extracellular traps (NETs)}

Neutrophils may kill the invading pathogens including viruses not only through engulfment of microbes, the formation of reactive oxygen species, degranulation, and secretion of antimicrobials but also through formation of NETs. NETs are networks of extracellular fibers, primarily composed of DNA from neutrophils that bind and kill extracellular pathogens while minimizing damage to the host cells [30]. Barnes et al. suggested that neutrophils may contribute to COVID-19 pathogenesis utilizing NETs, based upon autopsy findings. They also suggested that dornase alpha treatment may be beneficial for the management of this infection [31]. Transfer of DNA fragments to extracellular space may be due to the release of mitochondrial DNA together with disruption of the plasma membrane or caused by a process known as NETosis. NETosis is a type of programmed cell death distinct from apoptosis and necrosis. Viral RNA and proinflammatory cytokines may stimulate the formation of both NETs and NETosis. Although the exact role of NETs in anti-viral immunity has not been elucidated yet, they might contribute to COVID-19 pathogenesis [30-32].

\section{(4) Miscellaneous other mechanisms:}

Pyroptosis is a highly inflammatory and Caspase-1dependent form of programmed cell death that occurs most frequently upon infection with intracellular pathogens and is part of the antimicrobial response. It has been postulated that pyroptosis with rapid plasma-membrane rupture and release of proinflammatory intracellular contents may also play a role in COVID-19 pathogenesis. Rapid viral replication that causes increased pyroptosis may lead to a massive release of inflammatory mediators [33, 34].

Liu et al. emphasized the importance of antibodies against spike glycoprotein (anti-S-IgG) as promoters of proinflammatory monocyte/macrophage accumulation in the lungs. They suggested that viral-specific antibody response may cause pathological changes, which may be responsible for virusmediated lung injury [35]. Golonka et al. speculated that glycoprotein $\mathrm{S}$ protein on coronaviruses may undergo a conformational change and enter the host cells through the $\mathrm{Fc}$ region of IgG. In other words, they proposed a mechanism permitting antibody-dependent enhancement of viral entrance to host cells [32].

As discussed above, the corruption of hem metabolism may be one of the causes of high serum free iron levels and may contribute to inflammation [8]. Recently, iron-mediated cell death, known as ferroptosis, was reported to play a role in pathogenesis miscellaneous diseases $[35,36]$. The role of ferroptosis in COVID-19 pathogenesis and its place as a treatment target should be investigated.

Taken together, viral escape mechanisms to avoid anti-viral immunity, together with genetic or acquired defects in host defense, may impair viral clearance, resulting in MAS and inappropriate immune activation, causing ARDS and multiorgan failure. Why disease course is variable ranging from asymptomatic to lethal may be explained by genetic and host factors [37]. This may also explain why the number of deaths may be high in some families. Given that genetic factors also play a role in primary HLH/MAS cases, a meta-analysis was performed to analyze both the countries where HLH/MAS cases are frequently reported and where the frequency of severe and lethal COVID-19 infections are high [38]. Interestingly, geographical distributions were found to be similar. Genetic mutations causing a tendency for primary HLH may constitute a risk factor for severe disease course in COVID-19. Just the opposite, familial Mediterranean fever 
(FMF)-associated genetic mutations may be speculated to confer milder disease course, based upon the historical hypothesis claiming that such mutations may confer resistance to some viral and bacterial pathogens. Indeed, lower death ratios in COVID-19 infections reported from Turkey and Israel may support this speculation (based on https:// covid19.who.int/accessed in 25.04.2020). Interestingly, MAS occurrence is not frequent in FMF despite being an autoinflammatory disease [39].

\section{Management of the potential immunologic complications of COVID-19 infection}

Besides anti-viral agents, treatment of immunologic complications including cytokine storm using appropriate immunosuppressive and immunomodulatory drugs is essential [40, 41]. Currently, there is no specific anti-viral agent or vaccine available for COVID-19. However, there are many drugs, most of which are familiar to rheumatologists, which are used based on their pharmacological properties. Corticosteroids (CS), chloroquine (CQ), hydroxychloroquine (HCQ), IL-6R antagonists including tocilizumab (TCZ), IL-1 antagonists including anakinra, TNF inhibitors, and Janus kinase inhibitors are among those agents used for this purpose [5, 9], On the other hand, non-steroidal anti-inflammatory agents, especially ibuprofen, are not recommended in the treatment of COVID19 infection because of the observations that they may exacerbate the symptoms by increasing the ACE- 2 expression [42].

\section{Chloroquine and Hydroxychloroquine}

These two antimalarial agents are commonly used in rheumatology practice for treating patients with rheumatoid arthritis (RA), systemic lupus erythematosus (SLE), and Sjögren's syndrome, based upon their immunomodulatory effects. Besides anti-malarial effects, CQ and HCQ have been reported to have anti-viral activity against many viruses such as dengue, Ebola, SARS, and H5N1 in the past. Recently, they were reported also to be useful for COVID-19 and were included in the guidelines of many countries including China and Italy [43-49].

$\mathrm{CQ}$ and HCQ accumulate in lysosomes and raise the $\mathrm{pH}$ level of the endosome, which may interfere with virus entry and/or exit from host cells [48]. Besides, these two agents may interfere with the ACE-2 receptors, which SARS-CoV-2 upregulate their expression and enter the cell by binding to these receptors. CQ and HCQ may reduce glycosylation of ACE-2 receptors, thereby preventing SARS-CoV-2 from effectively binding to host cells $[48,49]$. Recently, Wenzhonget al. claimed that antimalarials might block the binding of the SARS Cov-2 virus to porphyrins and thus prevent the entering of the virus to the cell [8]. Finally, they might block the production of pro-inflammatory cytokines including IL-6, thereby blocking the pathway that subsequently leads to ARDS. Whatever the mechanisms are, multicenter studies performed in China reported beneficial effects of these agents among patients with COVID-19 [49]. Although there are some opposite reports, it seems that CQ and HCQ will remain as main drugs for COVID-19.

One may wonder whether rheumatology patients already receiving HCQ may be protected from COVID-19 infections. Recently, 22 patients with rheumatic diseases and receiving HCQ treatment were reported to have COVID-19 infection and one of them died. Although the results of this study have not been reported yet, it seems that prophylactic treatment with HCQ may not prevent COVID-19 infection (Twitter trial) (https://twitter.com/rheum_covid). We also observed that some of our patients developed COVID-19 while receiving HCQ. But rheumatic patients frequently have co-morbidities and use many other drugs as well. Also, the usual daily dose of HCQ is $200 \mathrm{mg}$, which is below the recommended dose for COVID-19. Therefore, we do not recommend prophylactic use of HCQ to prevent COVID-19 infection.

\section{Janus kinase inhibitors}

COVID-19 may enter inside the cell by endocytosis and invade the cell. AP2-associated protein kinase I (AAK1) is a member of the numb-associated kinase (NAK) family, which serves as a clathrin-mediated endocytosis regulator, and AAK1 inhibitors may prevent viral entry into the cell [40, 50]. Baricitinib is an inhibitor of the JAK-STAT pathway, which is used for suppressing proinflammatory cytokine production and systemic inflammation in RA. Baricitinib is also a NAK inhibitor, with a particularly high affinity for AAK [40, 51]. Based upon this basic data, Stebbing J et al. suggested that baricitinib2-4 mg daily may be combined with antiviral treatment in severe COVID-19 infections [40]; however, inhibition of IFN production as a result of concomitant JAKSTAT pathway blockage may cause impairment of anti-viral immunity [52]. On the other hand, tofacitinib cannot inhibit AAK1 and is not recommended for this purpose [40]. The tendency for general infections and the possibility of diverticulitis are other disadvantages of JAK inhibitors [50].

\section{Interleukin-6 inhibitors}

As mentioned above SARS and COVID-19 infections may cause MAS and cytokine storm. T lymphocytes are hyperactivated, and there is an enormous amount of proinflammatory cytokines including IL-6 and IL-1, which contribute to vascular permeability, plasma leakage, and DIC, thereby causing pulmonary damage and ARDS, as well as multi-organ failure [22]. Cytokine storm and related 
similar problems are also observed after the chimeric antigen receptor $\mathrm{T}$ cell (CAR-T) treatment [53].

TCZ is a humanized anti-IL-6 receptor antibody, inhibiting IL-6. TCZ is currently used not only for therapy of RA, temporal arteritis, and many other autoimmune rheumatic diseases [54] but also for the treatment of the cytokine storm, which may be induced by CAR-T treatment [53].

Based on these observations, TCZ treatment was also tried in patients with severe SARS-CoV-2 infection complicated with cytokine storm and ARDS. Retrospective studies from China reported the resolution of fever and hypoxemia and improvement in serum CRP levels and pulmonary CT findings [40, 41, 55-57]. Our own experience is also consistent with these reports. For the treatment of cytokine storm, the recommended TCZ dose is $8 \mathrm{mg} / \mathrm{kg}$ IV as single or divided two doses by $12-24 \mathrm{~h}$ intervals (maximum dose $800 \mathrm{mg}$ ). Tendency for general infections, hepatotoxicity, hypertriglyceridemia, and the possibility of diverticulitis are the main disadvantages of TCZ treatment [58].

\section{Interleukin-1 inhibitors}

As mentioned above, IL-1 is another proinflammatory cytokine playing a dominant role in a cytokine storm, and SARS$\mathrm{CoV}-2$ may cause pyroptosis by IL- $1 \beta$ [5]. Anakinra is a recombinant IL-1R antagonist (rHIL-1Ra) and is the first IL1 blocking biologic agent produced. Anakinra blocks the binding of both IL- $1 \alpha$ and IL- $1 \beta$ to IL-1R, thereby inhibits the proinflammatory effects of IL-1 [59]. Anakinra was found to be beneficial in patients with severe sepsis without significant adverse effects based upon the data of phase 3 randomized clinical trial [60]. The recommended SC adult dose of anakinra ranges from 100 to $200 \mathrm{mg}$ daily to $100 \mathrm{mg}$ three times weekly; the pediatric dose is $1 \mathrm{mg} / \mathrm{kg}$ daily. The bioavailability of SC injections is $95 \%$ with a half-life of $4-6 \mathrm{~h}$. In the presence of renal failure (GFR $<30 \mathrm{ml} / \mathrm{min}$ ), it should be given in every 2 days. Hepatic disease does not require dose adjustment. Unlike TCZ, anakinra does not inhibit CRP synthesis directly; therefore, serum CRP levels can be used to follow up systemic acute phase response [59]. Another molecule produced for IL-blockage is canakinumab, which is a high affinity, fully humanized, monoclonal anti-IL-1 $\beta$ antibody with $\operatorname{IgG} 1 / \mathrm{K}$ isotype. Following $\mathrm{SC}$ injection of $150 \mathrm{mg}$, peak serum concentration is achieved in 7 days. The recommended dose interval is every 2 months [59]. The third molecule developed for IL-1 blockade is Rilonacept, which is a recombinant soluble IL-1 receptor. The half-life of rilonacept is 6.3-8.6 days. The recommended loading dose is $2.2 \mathrm{mg} / \mathrm{kg}$, with the maximum dose of $160 \mathrm{mg}$; the maintenance dose is half of the loading dose weekly [61]. The use of canakinumab or rilonacept for severe COVID-19 infections has not been reported yet.

\section{TNF-a inhibitors}

TNF- $\alpha$ is a key proinflammatory cytokine contributing to various acute and chronic inflammatory pathologies, including some autoimmune diseases and septic shock. Anti-TNF agents are commonly used for the treatment of rheumatoid arthritis, ankylosing spondylitis, and psoriatic arthritis. While serum TNF- $\alpha$ levels were moderately elevated in patients with SARS, much higher serum levels were observed in patients with COVID-19 infection, positively correlated with disease severity. Although anti-TNF treatment was suggested as a potential treatment for COVID-19, there is no sufficient data $[40,41]$.

\section{Corticosteroids}

Systemic corticosteroid (CS) treatment is controversial in severe ARDS; nevertheless, many physicians use this treatment in patients with severe viral ARDS. Its use is not recommended for patients with COVID-19, based on the data from patients with H1N1, SARS, and MERS [5]. International guidelines recommend using moderate doses of systemic CS treatment for a short time, only when hemodynamic parameters are not improved following fluid replacement and vasopressor support [40, 41]. Current use of systemic corticosteroid treatment during COVID19 infection is limited to patients having lethal complications related to cytokine storm such as ARDS, acute cardiac injury, renal failure, and to those patients with higher serum levels of D-Dimer. Since, there is no positive evidence coming from randomized clinical trials, WHO guideline dated March 13, 2020 does not recommend using systemic CS treatment for patients with COVID19 routinely [62]. In our opinion, methylprednisolone $40 \mathrm{mg}$ once daily for 4-5 days, in addition to TCZ treatment, may be helpful during cytokine storm and may also help to avoid rebound after TCZ.

\section{Intravenous immunoglobulin (IVIG)}

IVIG contains the pooled polyclonal immunoglobulin $\mathrm{G}$ (IgG) supplied from the plasma of approximately a thousand or more healthy blood donors. In clinical practice, IVIG is used in patients with immune deficiencies for the treatment of infectious diseases, as well as in treatment-resistant patients with autoimmune diseases as an immunomodulatory agent. Previous favorable experience from patients with SARS and MERS suggested the use of a high dose of IVIG $(0,3-$ $0,5 \mathrm{~g} / \mathrm{kg}$ ) in patients with serious COVID-19 infection in the early phase of the disease $[63,64]$. Anticoagulation and hydration should not be overlooked for increased tendency to thrombosis during IVIG treatment for COVID-19 patients. 


\section{Colchicine}

Colchicine is an anti-inflammatory and immunomodulatory agent, commonly used for the treatment of gout, FMF, and Behçet's syndrome for a long time. Colchicine was suggested to be useful for the treatment of some complications of COVID-19 infection, based on its ability to inhibit IL-1 production [41]. COLCORONA (Colchicine Coronavirus SARS-CoV2) trial is a phase 3, multi-center, randomized, double-blind, placebo-controlled multicenter study to evaluate the efficacy and safety of colchicine in adult patients diagnosed with COVID-19 infection and have at least one highrisk criterion. Currently, the results of this study have not been reported yet (ClinicalTrials.gov Identifier: NCT04322682).

\section{Other treatments}

Many other drugs and interventions were also proposed for the treatment of COVID-19 and its complications. The use of low molecular weight heparin (LMWH) or unfractionated heparin, at doses indicated for prophylaxis of venous thromboembolism, strongly advised in all COVID-19 patients hospitalized. If patients have a contraindication for anticoagulation, they should be treated with lower limb compression [65].

For the prevention and treatment of cytokine storm and possible lung fibrosis after COVID-19 pneumonia, mesenchymal stem cells (MSCs)-based immunomodulation treatment has been proposed as a suitable therapeutic approach. For this purpose, many studies are currently ongoing [66]. Leng et al. concluded that IV transplantation of MSCs was safe and effective in patients with COVID-19 pneumonia, especially for those in critically severe conditions [67]. However, currently, there are no approved MSC-based approaches for the prevention and/or treatment of COVID-19 patients, but the first results of clinical trials seem promising.

Immune plasma transfusion, which is a passive immunization way, is an old method used in the treatment of many infections. Experience with SARS-CoV infection showed that this treatment could work when given to the appropriate patient or even to family members caring for COVID-19 patients at home [68]. However, based upon the experience from SARS-CoV and MERS-CoV infections, there is a risk of antibody-mediated disease enhancement after hyperimmune globulin transfusion [69].

\section{Discussion and conclusion}

In this short review, the relation between pandemic COVID19 infection and its immunologic complication MAS was briefly debated. The mechanisms involved in cytokine storm development and why this complication occurs in some patients during COVID-19 infection were discussed and possible therapies reviewed. This study has some limitations. Firstly, the literature about COVID is changing at great speed and the Chinese literature could not be included in the manuscript. The lack of standard published studies and the differences in the treatment approaches between Chinese and Western sources (such as Chinese medicine) remained an obstacle for making correct recommendations.

Although SARS-CoV-2 infections may be asymptomatic or cause only mild symptoms in most of the cases, immunologic complications such as MAS and cytokine storm may occur in some cases. Impairment of SARS-CoV-2 clearance due to genetic and viral features, lower levels of interferons, increased neutrophil extracellular traps and NETosis, and increased pyroptosis create a background for such complications. The presence of genetic mutations causing a tendency for primary HLH may constitute a risk factor for severe disease course in COVID-19.

Once, immunologic complications like MAS/HLH occur, anti-viral treatment alone is not enough and should be combined with appropriate anti-inflammatory treatment. Early recognition and appropriate treatment of MAS and cytokine storm will decrease the morbidity and mortality in COVID-19 infection, which requires the collaboration of infectious disease, lung, and intensive care unit specialists with other experts such as immunologists, rheumatologists and, hematologists.

Author contributions As of April 11, 2020, data were started to be collected by Mehmet Soy and turned into article. The article reviewed by Gokhan Keser, Pamir Atagündüz, Fehmi Tabak, Isik Atagündüz, and Servet Kayhan and structured as last version. The data were carefully reviewed hematologically by Isik Atagündüz, and additional contributions were made to the article with literature recommendations.

Figure have been produced by Pamir Atagündüz.

Data availability Resource scanning was done in Google Academic and Pubmed with appropriate keywords. Original data in all studies (including case reports and case series) that addressed the definition, causes, and classification of COVID-19 and hemophagocytosis, MAS, hemophagocytic lymphohistiocytosis, and cytokine storm, published in the English language in peer-reviewed journals, were included.

Code availability No code or software.

\section{Compliance with ethical standards Disclosures None.}

Ethics approval It is a review article we have no ethical approval and we declared that all procedures performed in presents study were in accordance with the ethical standards of the institutional and/or national research committee and with the 1964 Helsinki declaration and its later amendments or comparable ethical standards.

Consent to participate All of the authors accepted last version of the article and signed the author's disclosure.

Consent for publication All of the authors accepted last version of the article for publication and signed the author's disclosure. 


\section{References}

1. Paules CI, Marston HD, Fauci AS (2020) Coronavirus infectionsmore than just the common cold. JAMA 323(8):707-708

2. Huang C, Wang Y, Li X, Ren L, Zhao J, Hu Y, Zhang L, Fan G, Xu J, Gu X (2020) Clinical features of patients infected with 2019 novel coronavirus in Wuhan, China. Lancet 395(10223):497-506

3. Crayne CB, Albeituni S, Nichols KE, Cron RQ (2019) The immunology of macrophage activation syndrome. Front Immunol 10:119. https://doi.org/10.3389/fimmu.2019.00119 eCollection 2019

4. Ding Y, He L, Zhang Q, Huang Z, Che X, Hou J, Wang H, Shen H, Qiu L, Li Z etal (2004) Organ distribution of severe acute respiratory syndrome (SARS) associated coronavirus (SARS-CoV) in SARS patients: implications for pathogenesis and virus transmission pathways. J Pathol; 203:622-630. https://doi.org/10.1002/path.1560

5. Sarzi-Puttini P, Giorgi V, Sirotti S, Marotto D, Ardizzone S, Rizzardini G, Antinori S, Galli M (2020) COVID-19, cytokines and immunosuppression: what can we learn from severe acute respiratory syndrome? Clin Exp Rheumatol 38(2):337-342

6. Li X, Geng M, Peng Y, Meng L, Lu S (2020) Molecular immune pathogenesis and diagnosis of COVID-19. J Pharm Anal. https:// doi.org/10.1016/j.jpha.2020.03.001 Online ahead of print

7. Read R (2020) Flawed methods in "COVID-19: attacks the 1-beta chain of hemoglobin and captures the porphyrin to inhibit human heme metabolism". ChemRxiv Preprint. https://doi.org/10.26434/ chemrxiv.12120912.v1

8. Wenzhong L, Hualan L (2020) COVID-19:attacks the 1-beta chain of hemoglobin and captures the porphyrin to inhibit human heme metabolism. ChemRxiv Preprint. https://doi.org/10.26434/ chemrxiv.11938173.v8

9. Zhang W, Zhao Y, Zhang F, Wang Q, Li T, Liu Z, Wang J, Qin Y, Zhang X, Yan X (2020) The use of anti-inflammatory drugs in the treatment of people with severe coronavirus disease 2019 (COVID19): the experience of clinical immunologists from China. Clin Immunol: 108393

10. Zhang B, Zhou X, Zhu C, Feng F, Qiu Y, Feng J, Jia Q, Song Q, Zhu B, Wang J (2020) Immune phenotyping based on neutrophilto-lymphocyte ratio and $\mathrm{IgG}$ predicts disease severity and outcome for patients with COVID-19. medRxiv. https://doi.org/10.1101/ 2020.03.12.20035048

11. Li L, Chen MX (2020) Critical patients with coronavirus disease 2019: risk factors and outcome nomogram. J Inf Secur 80(6):e37e38. https://doi.org/10.1016/j.jinf.2020.03.025

12. Terpos E, Ntanasis-Stathopoulos I, Elalamy I, Kastritis E, Sergentanis TN, Politou M, Psaltopoulou T, Gerotziafas G, Dimopoulos MA (2020) Hematological findings and complications of COVID-19. Am J Hematol. https://doi.org/10.1002/ajh.25829 Online ahead of print

13. Lin L, Lu L, Cao W, Li T (2020) Hypothesis for potential pathogenesis of SARS-CoV-2 infection - a review of immune changes in patients with viral pneumonia. Emerg Microbes Infect 9(1):727732. https://doi.org/10.1080/22221751.2020.1746199

14. Xu Z, Shi L, Wang Y, Zhang J, Huang L, Zhang C, Liu S, Zhao P, Liu H, Zhu L (2020) Pathological findings of COVID-19 associated with acute respiratory distress syndrome. Lancet Respir Med 8(4): 420-422

15. Yao X, Li T, He Z, Ping Y, Liu H, Yu S, Mou H, Wang L, Zhang H, $\mathrm{Fu} \mathrm{W} \mathrm{(2020)} \mathrm{A} \mathrm{pathological} \mathrm{report} \mathrm{of} \mathrm{three} \mathrm{COVID-19} \mathrm{cases} \mathrm{by}$ minimally invasive autopsies. Zhonghua bing li xue za zhi=. Chin J Pathol 49(0):E009. https://doi.org/10.3760/cma.j.cn11215120200312-00193

16. Zhang Y, Xiao M, Zhang S, Xia P, Cao W, Jiang W, Chen H, Ding $\mathrm{X}$, Zhao H, Zhang H Covid-19 cases: coagulopathy and antiphospholipid antibodies in patients with Covid-19. N Engl J Med 382(17):e38. https://doi.org/10.1056/NEJMc2007575
17. Schnappauf O, Chae JJ, Kastner DL, Aksentijevich I (2019) The Pyrin inflammasome in health and disease. Front Immunol 10:1745

18. Lucherini OM, Rigante D, Sota J, Fabiani C, Obici L, Cattalini M, Gattorno M, Cantarini L (2018) Updated overview of molecular pathways involved in the most common monogenic autoinflammatory diseases. Clin Exp Rheumatol 36(Suppl 1):3-9

19. Barrat FJ, Elkon KB, Fitzgerald KA (2016) Importance of nucleic acid recognition in inflammation and autoimmunity. Annu Rev Med 67:323-336

20. Zalinger ZB, Elliott R, Rose KM, Weiss SR (2015) MDA5 is critical to host defense during infection with murine coronavirus. J Virol 89(24):12330-12340

21. Crow MK, Ronnblom L (2019) Type I interferons in host defence and inflammatory diseases. Lupus Sci Med 6(1):e000336

22. Al-Samkari H, Berliner N (2018) Hemophagocytic lymphohistiocytosis. Annual review of pathology: mechanisms of disease. 13:27-49. https://doi.org/10.1146/annurev-pathol020117-043625

23. Mehta P, McAuley DF, Brown M, Sanchez E, Tattersall RS, Manson JJ (2020) COVID-19: consider cytokine storm syndromes and immunosuppression. Lancet 395(10229):1033-1034

24. Min C-K, Cheon S, Ha N-Y, Sohn KM, Kim Y, Aigerim A, Shin HM, Choi J-Y, Inn K-S, Kim J-H (2016) Comparative and kinetic analysis of viral shedding and immunological responses in MERS patients representing a broad spectrum of disease severity. Sci Rep 6:25359. https://doi.org/10.1038/srep25359

25. Snijder EJ, Van Der Meer Y, Zevenhoven-Dobbe J, Onderwater JJ, van der Meulen J, Koerten HK, Mommaas AM (2006) Ultrastructure and origin of membrane vesicles associated with the severe acute respiratory syndrome coronavirus replication complex. J Virol 80(12):5927-5940

26. Lamborn IT, Jing H, Zhang Y, Drutman SB, Abbott JK, Munir S, Bade S, Murdock HM, Santos CP, Brock LG (2017) Recurrent rhinovirus infections in a child with inherited MDA5 deficiency. J Exp Med 214(7):1949-1972

27. Junior AGD, Sampaio NG, Rehwinkel J (2019) A balancing act: MDA5 in antiviral immunity and autoinflammation. Trends Microbiol 27(1):75-85. https://doi.org/10.1016/j.tim.2018.08.007

28. To KF, Chan PK, Chan KF, Lee WK, Lam WY, Wong KF, Tang NL, Tsang DN, Sung RY, Buckley TA (2001) Pathology of fatal human infection associated with avian influenza A H5N1 virus. J Med Virol 63(3):242-246

29. Chan JF, Lau SK, To KK, Cheng VC, Woo PC, Yuen K-Y (2015) Middle East respiratory syndrome coronavirus: another zoonotic betacoronavirus causing SARS-like disease. Clin Microbiol Rev 28(2):465-522

30. Kaplan MJ, Radic M (2012) Neutrophil extracellular traps: doubleedged swords of innate immunity. J Immunol 189(6):2689-2695

31. Barnes BJ, Adrover JM, Baxter-Stoltzfus A, Borczuk A, CoolsLartigue J, Crawford JM, Daßler-Plenker J, Guerci P, Huynh C, Knight JS (2020) Targeting potential drivers of COVID-19: neutrophil extracellular traps. J Exp Med 217(6)

32. Golonka RM, Saha P, Yeoh BS, Chattopadhay S, Gewirtz AT, Joe B, Vijay-Kumar M (2020) Harnessing innate immunity to eliminate SARS-CoV-2 and ameliorate COVID-19 disease. Physiol Genomics 52(5):217-221. https://doi.org/10.1152/ physiolgenomics.00033.2020

33. Yang M (2020) Cell pyroptosis, a potential pathogenic mechanism of 2019-nCoV infection. SSRN: https://ssrn.com/abstract=3527420 or https://doi.org/10.2139/ssrn.3527420. Accessed 26 Apr 2020

34. Bergsbaken T, Fink SL, Cookson BT (2009) Pyroptosis: host cell death and inflammation. Nat Rev Microbiol 7(2):99-109

35. Liu L, Wei Q, Lin Q, Fang J, Wang H, Kwok H, Tang H, Nishiura K, Peng J, Tan Z (2019) Anti-spike IgG causes severe acute lung injury by skewing macrophage responses during acute SARS-CoV infection. JCI insight 4(4) 
36. Miotto G, Rossetto M, Di Paolo ML, Orian L, Venerando R, Roveri A, Vučković A-M, Travain VB, Zaccarin M, Zennaro L (2020) Insight into the mechanism of ferroptosis inhibition by ferrostatin1. Redox Biol 28:101328

37. Rouse BT, Sehrawat S (2010) Immunity and immunopathology to viruses: what decides the outcome? Nat Rev Immunol 10(7):514-526

38. Ramos-Casals M, Brito-Zerón P, López-Guillermo A, Khamashta MA, Bosch X (2014) Adult haemophagocytic syndrome. Lancet 383(9927):1503-1516

39. Rossi-Semerano L, Hermeziu B, Fabre M, Koné-Paut I (2011) Macrophage activation syndrome revealing familial Mediterranean fever. Arthritis Care Res 63(5):780-783

40. Stebbing J, Phelan A, Griffin I, Tucker C, Oechsle O, Smith D, Richardson P (2020) COVID-19: combining antiviral and antiinflammatory treatments. Lancet Infect Dis 20(4):400-402

41. Ferro F, Elefante E, Baldini C, Bartoloni E, Puxeddu I, Talarico R, Mosca M, Bombardieri S (2020) COVID-19: the new challenge for rheumatologists. Clin Exp Rheumatol 38(2):175-180

42. Day M (2020) Covid-19: ibuprofen should not be used for managing symptoms, say doctors and scientists. British Medical Journal Publishing Group

43. Gao J, Tian Z, Yang X (2020) Breakthrough: chloroquine phosphate has shown apparent efficacy in treatment of COVID-19 associated pneumonia in clinical studies. Biosci Trends 14(1):72-73. https://doi.org/10.5582/bst.2020.01047

44. Wang L-F, Lin Y-S, Huang N-C, Yu C-Y, Tsai W-L, Chen J-J, Kubota T, Matsuoka M, Chen S-R, Yang C-S (2015) Hydroxychloroquine-inhibited dengue virus is associated with host defense machinery. J Interf Cytokine Res 35(3):143-156

45. Akpovwa $\mathrm{H}$ (2016) Chloroquine could be used for the treatment of filoviral infections and other viral infections that emerge or emerged from viruses requiring an acidic $\mathrm{pH}$ for infectivity. Cell Biochem Funct 34(4):191-196

46. Savarino A, Di Trani L, Donatelli I, Cauda R, Cassone A (2006) New insights into the antiviral effects of chloroquine. Lancet Infect Dis 6(2):67-69

47. Yan Y, Zou Z, Sun Y, Li X, Xu K-F, Wei Y, Jin N, Jiang C (2013) Anti-malaria drug chloroquine is highly effective in treating avian influenza A H5N1 virus infection in an animal model. Cell Res 23(2):300-302

48. Vincent MJ, Bergeron E, Benjannet S, Erickson BR, Rollin PE, Ksiazek TG, Seidah NG, Nichol ST (2005) Chloroquine is a potent inhibitor of SARS coronavirus infection and spread. Virol J 2(1):69

49. Qiu T, Liang S, Dabbous M, Wang Y, Han R, Toumi M (2020) Chinese guidelines related to novel coronavirus pneumonia. Preprints:2020040207. https://doi.org/10.20944/preprints202004. 0207.v1

50. Jamilloux Y, El Jammal T, Vuitton L, Gerfaud-Valentin M, Kerever S, Sève P (2019) JAK inhibitors for the treatment of autoimmune and inflammatory diseases. Autoimmun Rev:102390

51. Richardson P, Griffin I, Tucker C, Smith D, Oechsle O, Phelan A, Stebbing J (2020) Baricitinib as potential treatment for 2019-nCoV acute respiratory disease. Lancet 395(10223):e30

52. Favalli EG, Biggioggero M, Maioli G, Caporali R (2020) Baricitinib for COVID-19: a suitable treatment? Lancet Infect Dis. https://doi.org/10.1016/S1473-3099(20)30262-0

53. Dholaria BR, Bachmeier CA, Locke F (2019) Mechanisms and management of chimeric antigen receptor T-cell therapy-related toxicities. BioDrugs 33(1):45-60

54. Ding C, Jones G (2006) Anti-interleukin-6 receptor antibody treatment in inflammatory autoimmune diseases. Rev Recent Clin Trials 1(3):193-200
55. McIntosh K (2020) Coronavirus disease 2019 (COVID-19). Edited by Martin S Hirsch. UpToDate, https://www.uptodate com/contents/coronavirus-disease-2019-covid-19. Accessed 26 Apr 2020

56. Bhimraj A, Morgan RL, Shumaker AH, Lavergne V, Baden L, Cheng V et al (2020) Infectious Diseases Society of America Guidelines on the Treatment and Management of Patients with COVID-19. Clin Infect Dis:ciaa478. https://doi.org/10.1093/cid/ ciaa478

57. Xu X, Han M, Li T, Sun W, Wang D, Fu B, Zhou Y, Zheng X, Yang Y, Li X (2020) Effective treatment of severe COVID-19 patients with tocilizumab. http://chinaxiv.org/abs/202003.00026. Accesed Apr 26th, 2020

58. Jones G, Ding C (2010) Tocilizumab: a review of its safety and efficacy in rheumatoid arthritis. Clin Med Insights: Arthritis Musculoskelet Dis 2010(3):81-89. https://doi.org/10.4137/ CMAMD.S4864

59. Şahin A, Derin ME, Albayrak F, Karakaş B, Karagöz Y (2020) Assessment of effectiveness of anakinra and canakinumab in patients with colchicine-resistant/unresponsive familial Mediterranean fever. Adv Rheumatol 60(1):12

60. Shakoory B, Carcillo JA, Chatham WW, Amdur RL, Zhao H, Dinarello CA, Cron RQ, Opal SM (2016) Interleukin-1 receptor blockade is associated with reduced mortality in sepsis patients with features of the macrophage activation syndrome: re-analysis of a prior phase III trial. Crit Care Med 44(2):275-281

61. Varan Ö, Kucuk H, Babaoglu H, Guven SC, Ozturk MA, Haznedaroglu S, Goker B, Tufan A (2019) Efficacy and safety of interleukin-1 inhibitors in familial Mediterranean fever patients complicated with amyloidosis. Mod Rheumatol 29(2):363-366

62. Wang M, Zhou Y, Zong Z, Liang Z, Cao Y, Tang H, Song B, Huang Z, Kang Y, Feng P (2020) A precision medicine approach to managing Wuhan coronavirus pneumonia. Precision Clin Med 3(1):14-21. https://doi.org/10.1093/pcmedi/pbaa002

63. Cao W, Liu X, Bai T, Fan H, Hong K, Song H, Han Y, Lin L, Ruan L, Li T (2020). High-dose intravenous immunoglobulin as a therapeutic option for deteriorating patients with coronavirus disease 2019. In: Open forum infectious diseases. 7(3). ofaa102, https:// doi.org/10.1093/ofid/ofaa102

64. Jawhara S (2020) Could intravenous immunoglobulin collected from recovered coronavirus patients protect against COVID-19 and strengthen the immune system of new patients? Int J Mol Sci 21(7):2272. https://doi.org/10.3390/ijms21072272

65. Marietta M, Ageno W, Artoni A, De Candia E, Gresele P, Marchetti M, Marcucci R, Tripodi A (2020) COVID-19 and haemostasis: a position paper from Italian Society on Thrombosis and Haemostasis (SISET). Blood Transfus. https://doi.org/10.2450/2020.0083-20

66. Golchin A, Seyedjafari E, Ardeshirylajimi A (2020) Mesenchymal stem cell therapy for COVID-19: present or future. Stem Cell Rev Rep:1-7. https://doi.org/10.1007/s12015-020-09973-w

67. Leng Z, Zhu R, Hou W, Feng Y, Yang Y, Han Q, Shan G, Meng F, Du D, Wang S (2020) Transplantation of ACE2-mesenchymal stem cells improves the outcome of patients with COVID-19 pneumonia. Aging Dis 11(2):216-228

68. Zhang JS, Chen JT, Liu YX, Zhang ZS, Gao H, Liu Y, Wang X, Ning Y, Liu YF, Gao Q (2005) A serological survey on neutralizing antibody titer of SARS convalescent sera. J Med Virol 77(2):147150

69. de Alwis R, Chen S, Gan ES, Ooi EE (2020) Impact of immune enhancement on Covid-19 polyclonal hyperimmune globulin therapy and vaccine development. EBioMedicine: 102768

Publisher's note Springer Nature remains neutral with regard to jurisdictional claims in published maps and institutional affiliations. 